\title{
UTOPIA, ENSAIO E TEMPESTADE: O NOVO MUNDO EM Morus, Shakespeare e Montaigne
}

UTOPIA, ESSAY AND TEMPEST:

More, Shakespeare and MontalGne ON THE NEW WORLD

Luciana Villas Bôas

ORCID 0000-0001-9933-6804

Universidade Federal do Rio de Janeiro

Departamento de Letras Anglo-Germânicas

Rio de Janeiro, RJ, Brasil

\section{Resumo}

Este artigo faz uma exploração de utopias letradas transmitidas ao longo de século XVI e início do XVII, enfocando um elemento específico das elucubraçôes humanistas: a ficção de encontros utópicos entre os mundos antigo e novo na Utopia de Thomas Morus, na Tempestade de Shakespeare e os Ensaios de Michel de Montaigne. Esses 'encontros' são, de fato, uma instância privilegiada de um imaginário político cuja articulação entrelaça a realização de um projeto humanista renascentista ao espaço recém-descoberto. Os ecos de Montaigne na Tempestade de Shakespeare são o ponto de partida para a investigação de aspectos controversos do imaginário político humanista renascentista em relação ao Novo Mundo e à colonização europeia.

Palavras-chaves: Morus, Montaigne, Shakespeare, Novo Mundo, Colonialismo europeu, Humanismo renascentista, Imaginário político.

\section{Abstract}

This article explores literary utopias transmitted in the course of the sixteenth century and beginning of the seventeenth century, focusing upon a specific element of humanist fancies: the fiction of Utopian encounters between the Ancient and the New World. In Thomas More's Utopia, William Shakespeare's The Tempest, and Michel de Montaigne's Essays. These 'encounters' are a privileged instance of the articulation of a political imagination that intertwines the realization of a Renaissance humanist project with the recently discovered space of the New World. Montaigne's echoes in Shakespeare's Tempest are the starting point for the investigation of

\section{Resumen}

Este articulo explora el tema de las utopías letradas transmitidas a lo largo del siglo XVI e inicios del XVII, focalizando un elemento específico de las elucubraciones humanistas: la ficción de encuentros utópicos entre los mundos antiguo y nuevo en la Utopia de Thomas Morus, en la Tempestad de Shakespeare y en los Ensayos de Michel de Montaigne. Esos 'encuentros' son, de hecho, una instancia privilegiada de un imaginario político, cuya articulación entrelaza la realización de un proyecto humanista renacentista al espacio recién descubierto. Los ecos de Montaigne en la Tempestade de Shakespeare son el punto de partida para la investigación de aspectos 
controversial aspects of Renaissance humanists' political imagination about the New World and the European colonization.

Keywords: More, Montaigne, Shakespeare, New World, European colonialism, Renaissance Humanism, Political imagination contradictorios del imaginario político humanista renacentista en relación con el Nuevo Mundo y la colonización europea.

Palabras claves: Thomas Moro, Montaigne, Shakespeare, Utopía, Nuevo Mundo, Colonialismo europeo, Humanismo renacentista, Imaginario político

Para o Pedro, meu irmáo

\section{Humanismo renascentista e imaginário político do Novo Mundo}

A relação entre a Tempestade de William Shakespeare (1611) e o colonialismo europeu tornou-se nas últimas décadas um locus classicus, ainda que conturbado, dos estudos (pós) coloniais. ${ }^{1}$ Nos acirrados, por vezes, virulentos debates, Próspero, o europeu invasor, e Caliban, o nativo subjugado, acabam roubando a cena de outros personagens. Figuras como o conselheiro Gonzalo, a encarnação mor do letrado humanista na peça, passam quase despercebidas, ou são relegadas a segundo plano. No entanto, é através de Gonzalo que a peça dá voz às utopias que humanistas renascentistas lançaram sobre o Novo Mundo. Em um discurso feito na condição de hipotético colonizador - "If I had plantation of this isle(...) and were the king of ' $\mathrm{t}$ " o conselheiro descreve como seria a constituição da ilha, se ele fosse o seu governante e, ao descrever a sua organização ideal, desfia o imaginário político sobre o Novo Mundo, que remonta à Utopia de Thomas Morus (1516) e se estende aos Ensaios de Michel de Montaigne (1580-1588). Mas, justamente quando se refaz o elo entre o personagem de Shakespeare, Morus e Montaigne, salta aos olhos que, no decorrer de um século, as condiçôes das projeçôes utópicas se transformaram. O diálogo de Gonzalo, o conselheiro do rei de Nápoles, com os cortesãos Sebastian e Antonio, náufragos, como ele, numa ilha incógnita, pode ser lido como uma encenação de posiçóes distintas, se não antagônicas, em relação às utopias políticas do humanismo renascentista.

1 As abordagens pós-coloniais são se limitam à identificaçăo de elementos da peça com a literatura da expansão, mas analisam os nexos da peça com a articulaçấo de um discurso colonialista no período. Para uma revisão das polêmicas travadas em torno da Tempestade ver Peter HULME e SHERMAN (2000) e Bernardo RICÚPERO (2014). Para uma discussão crítica e, ao mesmo tempo, inovadora, sobre a crítica pós-colonial, ver Daniel CAREY e Lynn FESTA (2009) 
Gonzalo: I' the commonwealth I would by contraries/Execute all things, for no kind of traffic/ Would I admit; no name of magistrate;/Letters should not be known; riches, poverty,/And use of service, none; contract, succession,/ Bourn, bound of land, tilth, vineyard, noe;/ No use of metal, iron, or wine, or oil;/ No occupation; all men idle, all, / And women too but innocent and pure; / No sovereignty -

Sebastian: Yet he would be king on 't.

Antonio: The latter end of his commonwealth forgets the beginning.

Gonzalo: All things in common nature should produce/ Without sweat or endeavor. Treason, felony,/ Sword, pike, knife, gun, or need of any engine/ Would I not have; but nature should bring forth,/ Off its own kind, all foison, all abundance,/To feed my innocent people. (...) I would to such perfection govern, sir, ? T' excel the Golden Age.

Sebastian: Save His Majesty!

Antonio: Long live Alonso!

(SHAKESPEARE [1611], 1988, p. 31-32)

Para a caracterização da "república" que Gonzalo instauraria "em oposição" à própria sociedade, Shakespeare serviu-se, diretamente, da versão de John Florio, o tradutor dos Ensaios de Montaigne para o inglês, publicada em 1603. A cadência que Florio deu ao ensaio "De canibais" é perceptível na fala do conselheiro, uma apropriação às vezes literal da tradução. Gonzalo toma de Montaigne a noção de um estado natural originário (FLORIO, 1603, p. 102: "original naturallitie"; MONTAIGNE, [1580], 1962, p. 204: "naifveté originelle"), cujos méritos superariam as representaçóes que os antigos deram à Idade de Ouro. O trecho da tradução de Florio que cito abaixo mostra como a existência dos cidadãos na república, que Gonzalo deseja instaurar, é diretamente moldada na natureza original, não "abastardada" dos Tupinambás de Montaigne (FLORIO, 1602, p. 102: "bastardized”); MONTAIGNE, [1580] 1962, I, 32, p. 204: “abastardies").

It is a nation (...) that hath no kind of traffike, no knowledge of Letters, no intelligence of numbers, no name of magistrate, nor of politique superiorities, no use of service, of riches, or of poverty; no contracts, no successions, no dividences, no occupation, but idle; (...) The very words that import lying, falshood, treason, dissimulation, covetousness, envie, detraction, and pardon, were never heard of amongst them. (FLORIO, 1603, p. 102)

Tanto a caracterização dos Tupinambás, em Montaigne, quanto a da república ideal, em Shakespeare, remetem explicitamente a modelos antigos, ainda que seja, numa atitude tipicamente humanista, para, ao mesmo tempo, 
endossar e exaurir as fontes. ${ }^{2}$ Gonzalo imagina-se capaz de implementar uma sociedade que "ultrapassaria a Idade de Ouro"; Montaigne, na feliz tradução de Florio, desafia imaginariamente Platão a relativizar a perfeição da sua república: "How dissonant would he finde his imaginary common-wealth from this perfection?" (FLORIO, 1603, p. 102). Ambos os textos estão inscritos num contexto intelectual no qual é inconcebível pensar sobre a natureza humana e a constituição política ideal sem considerar parâmetros estabelecidos em textos clássicos. ${ }^{3}$ Mas a comparação entre eles revela, também, uma diferença crucial no enlace entre um mundo novo e fontes antigas: os Tupinambás de Montaigne encarnam valores clássicos, no estado atual em que se encontram; a colônia ideal, na peça de Shakespeare, só existe num futuro condicional.

Antes de abordarmos diferenças, é preciso sublinhar, nos textos de Shakespeare e Montaigne, o recurso ao mesmo artifício: a encenação de um encontro real do mundo antigo com o novo. Dessa fabricação de uma comunidade real ou conjurada, do antigo e o novo, resulta o elemento propriamente 'utópico', que os une a um mesmo modelo literário. Pois, o encontro imaginário do mundo antigo com o novo já aparece, como não poderia deixar de ser, de forma exemplar, na Utopia de Thomas Morus. Na primeira parte do livrinho de Morus o leitor aprende que os utopienses puderam construir a melhor das repúblicas graças a um feliz acaso, ocorrido há mil e duzentos anos, quando antigos romanos e egípcios naufragaram nas praias de sua ilha: "Now note how the Utopians profited, through their diligence, from this one chance event. They learned every single useful art of the Roman civilization either directly from their guests or indirectly from hints and surmises on which they based their own investigations." (MORE, [1516] 2000, p. 41). A ficção sério-jocosa de uma sociedade que se educa, pautada em modelos antigos, de modo a tornar-se a mais perfeita república é um marco, uma declaração aberta do otimismo dos humanistas renascentistas em relação à aplicação dos studia humanitatis para o aprimoramento da vida em comum.

O que se segue é uma exploração de utopias letradas transmitidas ao longo do século XVI e início do XVII. Não pretendo oferecer um panorama das utopias que proliferaram na cultura europeia da época, mas, antes, perseguir um elemento específico das elucubraçóes humanistas: a projeção de encontros utópicos entre os mundos antigo e novo. $\mathrm{O}$ encontro dos jovens utopienses de Morus com náufragos antigos é paradigmático do estratagema

2 Para uma discussão nuançada da aplicação de modelos clássicos nas primeiras representaçóes do Novo Mundo, ver Christian Kiening, O Sujeito Selvagem. Pequena Poética do Novo Mundo, São Paulo: Edusp, 2014.

3 Sobre como os textos clássicos de filosofia moral, história, filosofia, retórica, gramática e poesia eram um "guia" indispensável ao conhecimento do mundo e à ação política, ver David Armitage, Conal Condren, and Andrew Fitzmaurice, 2009, p. 13. 
sério-jocoso cultivado por letrados humanistas. Esses 'encontros' são, de fato, uma instância privilegiada, e quase inexplorada pelos estudiosos, de um imaginário político cuja articulação entrelaça a realização de um projeto humanista renascentista ao espaço recém-descoberto do Novo Mundo. A fala utópica do personagem de Shakespeare, nesse contexto, funciona como um ponto de inflexão no âmbito dessas experimentaçôes. A partir dela é possível observar as condiçóes de enunciação de utopias letradas, assim como as posiçóes dos seus respectivos 'falantes' em relação ao "novo mundo" e à sua colonização. Ninguém se dedicou à fabricação de encontros utópicos entre os mundos novo e antigo como Montaigne. É por essa razão que concentro a minha análise nos seus Ensaios.

A atitude crítica de Montaigne em relação ao colonialismo europeu não é uma novidade. Mas o alcance da sua crítica permanece, ao menos em parte, indiscernível. Busco trazer para a discussão sobre o colonialismo europeu nos Ensaios um novo contexto. Nele, a crítica de Montaigne à colonização europeia do Novo Mundo implica a renúncia à expectativa articulada por Morus na Utopia. Morus acreditava na eficácia dos studia humanitatis para o conhecimento do mundo e a busca do bem comum. Em Morus, os habitantes do Novo Mundo demonstram exemplarmente o sucesso da aplicação dos studia humanitatis, da frequentação dos antigos, para a formação individual e a instauração do bom governo. Já em Shakespeare e Montaigne, o encontro imaginário dos habitantes do Novo Mundo com os antigos evidencia a incapacidade de os europeus se educarem e, portanto, também de colonizarem o Novo Mundo.

O Novo Mundo está no centro das indagações de Montaigne acerca dos limites da tradição, da inventio e, portanto, do projeto dos Ensaios como um todo (cf. VILLAS BÔAS, 2019, p. 145-162). Os encontros utópicos descritos por Montaigne levam-no a problematizar o valor epistemológico dos legados clássicos, dos studia humanitatis para se conhecer o Novo Mundo. Para além da pureza original ou maturidade virtual do diferentes habitantes do Novo Mundo, Montaigne examina os premissas que moldam essas percepçóes. O gesto socrático de interrogar não apenas o conhecimento, mas o sujeito conhecedor, acaba conduzindo também à análise de uma visão cíclica da história. Segundo essa noção, as culturas passariam necessariamente por fases pré-determinadas de desenvolvimento, moldadas desde a Antiguidae a partir das idades do ser humano, ou seja, a infância e a juventude, a maturidade e a decadência.

Os estudos sobre a concepçáo de tempo nos Ensaios voltaram-se, em geral, para a noçáo de exemplaridade, no âmbito de uma concepção da história como mestra da vida (HAMPTON, 1990; LYONS, 1989, 2016; KOSELLECK, 1989, p. 39-40). Neste artigo, diferentemente, procuro enfocar 
o questionamento que Montaigne faz da concepção cíclica de história e do lugar que nela ocupariam os habitantes do Novo Mundo. Observo, ainda, que a sua reflexão sobre o tempo está inextricavelmente associada a uma situação concreta: à degradação que o colonialismo europeu desencadeou no Novo Mundo. Os encontros escritos entre os mundos novo e antigo náo são um refúgio epicurista à imaginação do ensaísta. ${ }^{4}$ Eles integram o Novo Mundo, no presente, ao exercício crítico do juízo, transformando-o em um objeto de decisão.

Em primeiro lugar, num rápido esboço das utopias letradas de Thomas Morus, Shakespeare e Montaigne, traço os contornos de uma 'tradição' de textos dedicados ao Novo Mundo, ainda largamente negligenciada por nós. Em seguida, abordo os capítulos que Montaigne dedicou ao Novo Mundo, "De canibais", na primeira edição dos Ensaios (1580) e "De coches", no terceiro livro da edição ampliada que publicou em vida (1588). Os dois ensaios, afastados no tempo e no modo de composição, são estruturados em torno de encontros utópicos: no primeiro, os Tupinambás são recebidos pelo rei da França em Rouen, no segundo, os habitantes do México e do Peru são descobertos e colonizados pelos antigos romanos. Na última parte, relaciono o que Montaigne chamou de "inteligência do tempo" (MONTAIGNE, II, 13 , p. 588) à sua crítica ao colonialismo europeu, articulada abertamente no enigmático ensaio, "De coches".

\section{Ficções do Novo Mundo: Shakespeare entre Morus e Montaigne}

Nos três autores em questão, Morus, Montaigne e Shakespeare, os antigos são o fundamento das reflexóes sobre a natureza e a felicidade humanas; mas tornam-se, também, cada vez mais problemáticos. Em "De canibais", o ensaísta sustenta que os antigos jamais imaginaram uma existência tão "simples e pura" quanto a que ele e seus contemporâneos "viram, por experiência" existir entre os Tupinambás: "une nayfveté si pure et simple, comme nous la voyons par la experience" (MONTAIGE, [1580] 1962, p. 204). E, dirigindose diretamente a Platão - “C'est une nation, diroy je à Platon" - encena um diálogo imaginário com o filósofo para apresentar-lhe a organização social dos Tupinambás.

Il me displait que Licurgus et Platon ne l' ayent eüe; car il me semble que ce que nous voyons par par experience en ces nations lá, surpasse non seulement toutes les peintures de dequoy la poësie a embelly l'age doré et toutes ses inventions

4 Como se verá adiante, afasto-me das interpretaçóes que vêem na obra tardia de Montaigne uma afirmação epicurista do instante presente e, assim, inadvertidamente, impóem uma moldura teleológica aos Ensaios, por definição inconclusos, de tal modo que o autor continuou a rever e escrever neles, até a sua morte, em 1592 . 
à feindre une hereuse condition d'hommes, mais encore la conception et le desir mesme de la philosophie. (MONTAIGNE, I, 31, p. 204)

$\mathrm{Na}$ medida em que desafiam as concepções antigas da natureza e felicidade humanas, "o desejo de filosofia," o Novo Mundo, como se verá mais adiante, está no coração do projeto que Montaigne persegue nos Ensaios, o de fazer um retrato do seu eu "simples, naturelle et ordinaire", anterior à cultura e suas convençóes (MONTAIGE, [1580] 1962, "Au lecteur", p. 2). Ao mesmo tempo, Montaigne lamenta que o Novo Mundo não tenha sido descoberto antes, pelos antigos que, ao contrário dos contemporâneos europeus, seriam seres humanos infinitamente mais capazes de "julgar" a sua "pureza”. O deslocamento da descoberta do Novo Mundo para a antiguidade - "du temps qu'il y avoit des hommes qui en eussent mieux juger que nous" (MONTAIGNE, [1580] 1962, I, 31, p. 204) - assim como a suspeita de que o contato com os europeus levará à ruína dos seus habitantes são aqui apenas insinuados. Serão retomados e amplificados no ensaio posterior, "De coches", de 1588.

$\mathrm{Na}$ Tempestade, a fala do conselheiro Gonzalo também evoca um encontro imaginário entre o antigo e o novo; mas, em lugar da experiência de uma alteridade radical, há a projeção de atributos de antigas visôes da Idade de Ouro sobre um mundo novo, recém-descoberto. O viés republicano e especular, "by contraries", do seu projeto o aproxima de Morus. Mas, à diferença do autor da Utopia, Gonzalo revela-se um utopista. O letrado exilado fala de um "não-lugar" estando, ele próprio, fora do lugar, em lugar nenhum. A utopia de Morus está localizada em um espaço, uma ilha do Novo Mundo, longamente explorada por um português, filósofo e viajante, chamado Rafael Hitlodeu, cujo relato More, o "autor", reduzido a relator, alega registrar. O verdadeiro "autor", Hitlodeu, não é o criador, mas o "descobridor" da ilha. Morus tenta, em vão, persuadir o perito em Utopia a tornar-se conselheiro de príncipes. Ele, que será o futuro conselheiro de Henrique VIII, não consegue convencer o filósofo-viajante a ingressar na vida ativa; mas leva à esfera do público, sob a forma de livro, o seu conhecimento utópico (cf. VILLAS BÔAS, 2017, p. 302). A dicção sério jocosa, o serio ludere do encômio paradoxal de More (u-topia quer dizer não-lugar, Hitlodeu, perito em bagatelas), sem dúvida abala a factibilidade da utopia republicana. Mas o livrinho não deixa de ser uma aposta na eficácia cívica da educação, e uma afirmação da virtude como fundamento da verdadeira nobreza humana.

Gonzalo, diferentemente de Hitlodeu, não adquire a sua perícia em "utopia" através da experiência, mas da leitura de modelos clássicos; ao contrário do filósofo português, está certo de que, em condições ideais que de fato não estão dadas e são, por isso, contrafactuais - ele seria capaz 
de instaurar as condiçóes para a sua factibilidade. Assim, posto na situação concreta de letrado exilado numa ilha desconhecida, declara que, se tivesse a autorização para colonizar a ilha, e fosse o soberano dela, o seu "rei", implementaria a mais perfeita república que já se viu. O seu programa de governo não é endossado por nenhum personagem da peça. Pelo contrário, os interlocutores, Sebastian e Antonio, debocham do caráter paradoxal do seu programa de governo: a necessidade de um monarca para instituir um regime republicano, a circunstância de que o fim do projeto político dissimula o seu início ("The latter end of his commonwealth forgets the beginning"). Depois de fazer o seu discurso utópico, como se, caindo em si, tivesse retornado à sua condição de mero conselheiro, Gonzalo dirige-se a Alonso para saber se o rei ainda lhe dá ouvidos ("And - do you mark me sir?"). A resposta real é, na sua ambiguidade cômica, duplamente aniquiladora: uma declaração de que o que o letrado disse é nada, um pedido para que não diga mais nada: "Prithee, no more. Thou dost talk nothing to me." Através de Gonzalo, a peça de Shakespeare parece denunciar que a utopia republicana esbarra na contradiçáo entre projeto e factibilidade, virtude e poder. Ao mostrar que o enlevo utópico separa a criação da realização, acaba desmascarando a condição paradoxal da aboliçáo da monarquia: a pretensão de soberania.

$\mathrm{Na}$ Tempestade, Shakespeare está longe de idealizar os possíveis enlaces entre o humanismo renascentista e o exercício do poder, seja no velho, ou Novo Mundo. Através da figura de Gonzalo, a peça evoca o contexto colonial, o Novo Mundo, como um espaço propício ao exercício da virtude, à fundação e conservação do bem comum. Mas a ilha encantada está longe de cumprir a promessa de ser o espaço por excelência para se instituir, por meio da persuasão e da oratória, um novo "commonwealth". Gonzalo é virtuoso, mas não é bom orador, mostra-se incapaz de persuadir seus ouvintes, de conquistar a atenção do rei e, portanto, de desempenhar a função de conselheiro. ${ }^{5}$ Próspero, um duque letrado que no início da peça preferia os livros da sua biblioteca aos súditos do seu ducado, passa de governante ingênuo e passivo a soberano tirânico que não hesita em recorrer, no lugar da persuasão, ao medo e à violência como instrumentos de dominaçáo. A peça turva a confiança, que ainda se verificava em More, na relevância dos studia humanitatis como um meio para se alcançar o bem comum. Na ilha tempestuosa, a frequentação dos clássicos não define os fins da colonização. Próspero fracassa como educador humanista, uma vez que o seu aluno, o nativo Caliban, não aprende a arte da persuasão, mas a fazer injúrias. No final, aconselhado pelo espírito Ariel,

5 Poderíamos dizer que Gonzalo é um personagem anti-ciceroniano, na medida em que nele não coincidem a virtude e a arte da persuasão. Sobre a 'virada maquiaveliana' de Shakespeare, ver FITZMAURICE, 2003, p. 171-177. 
Próspero reconcilia-se com os seus inimigos e, abandonando qualquer projeto colonial, retorna à Itália.

Não posso investigar aqui se o abandono do experimento insular significa também o abandono do Novo Mundo como espaço, por excelência, da ficção política. Penso, contudo, que o fim da peça marca uma despedida do Novo Mundo como terreno imaginário propício à realizaçáo de uma sociedade voltada para o bem comum. ${ }^{6}$ Estudos sobre o humanismo renascentista e o colonialismo inglês apontam para um crescente ceticismo em relação às esperanças inicias de se reconciliarem, no projeto colonial, interesse e virtude, poder e persuasão: "the landscape of political thought and of postReformation politics shifted away from ideals of Ciceronian virtue toward a more Machiavellian and Tacitean world" (ARMITAGE, CONDREN, FITZMAURICE, 2009, p. 13). A comparação da Tempestade com a Utopia de Morus parece confirmar o diagnóstico. Não se trata de imputar a Morus, católico e humanista, a factibilidade terrena da mais perfeita república e, portanto, a perfectibilidade da natureza humana. Mas apenas de ressaltar a aposta humanista na eficácia dos studia humanitatis na vida ativa, no bem comum. Nesse sentido, Montaigne guarda uma comunidade espiritual com o ceticismo de Shakespeare. Basta lembrar, para não nos afastarmos muito dos textos abordados, do final do ensaio "De canibais". Depois de todo esforço para arrancar os "canibais" do senso comum, Montaigne, num arroubo de ironia, retorna ao cúmulo do paroquialismo: "Tout cela ne va pas trop mal: mais quoy, ils ne portent point de haut de chausses!" (MONTAIGNE, [1580] 1962, I, 31, p. 213).

Outro ponto importante à comparação entre a Utopia, os Ensaios e a Tempestade diz respeito ao deslocamento da própria utopia. Na Tempestade, as qualidades utópicas não são intrínsecas ao Novo Mundo, mas à imaginação de um letrado. A constituição política originária, igualitária e feliz, deixa de ser uma qualidade do Novo Mundo para se tornar o projeto de um letrado. Significativamente, à exceção do nativo Caliban, é notável a ausência de habitantes originais na ilha. O personagem Caliban evoca um arremedo dos monstrengos que, de acordo com o senso comum, proliferavam nas terras recém-descobertas. Fabricados a partir da reciclagem de monstrengos de textos antigos, os primeiros relatos impressos sobre o Novo Mundo sáo o pano de fundo ao qual Morus, i.e., Rafael Hitlodeu, o viajante perito em utopia, contrapóe os seus bem-governados e virtuosos utopienses: "We made no inquiries, however, about monsters, which are the routine of travellers' tales. Scyllas, ravenous Celaenos, man-eating Lestrygonians and that sort of monstrosity you can hardly avoid, but to find governments wisely established

6 Sobre o pessimismo e a 'virada maquiaveliana' de Shakespeare, ver FITZMAURICE, 2003, p. 171-177. 
and sensibly ruled is not easy." (MORUS, [1516], 1989, p. 12). Já Montaigne, no que diz respeito à humanidade do Novo Mundo, insiste na pureza e na originalidade como qualidades intrínsecas aos habitantes da França Antártica, no primeiro ensaio, ou nas virtudes clássicas das "naçôes" do Peru e do México, no segundo. Afastado nesse quesito de Shakespeare, parece aproximar-se de Morus. Mas, na verdade, as diferenças são flagrantes. Os utopienses deixamse educar pelos antigos romanos e egípcios que naufragaram em sua ilha. Tornaram-se utópicos, graças ao encontro com os antigos. Em Montaigne, em seu primeiro ensaio, sobre os "canibais", o encontro com os antigos assume outra função. Aqui também, apenas no futuro condicional, à moda de um experimento de pensamento. $\mathrm{Na}$ eventualidade fictícia de uma descoberta antecipada do Novo Mundo, se os antigos soubessem "julgar" os selvagens, seriam levados a rever a sua "concepçáo e o seu desejo de filosofia" e, assim, seriam por eles reeducados.

Antes de passarmos aos ensaios de Montaigne, um brevíssimo comentário sobre o posicionamento dos textos em relaçáo à colonização do Novo Mundo. Vale a pena lembrar a discreta mas decisiva observação em Morus de que os próprios utopienses eram colonizadores exitosos. Tirando essa circunstância, que sugere uma certa naturalização da sujeição de povos selvagens por outros civilizados, Morus não entra no mérito da expansão colonial ibérica - os ingleses estavam longe de ter qualquer parte na expansão. A peça de Shakespeare, escrita depois das primeiras tentativas coloniais inglesas, culmina no fracasso retumbante do governo colonial de Próspero, no abandono do único nativo assujeitado, e no restabelecimento da ordem italiana, inicialmente usurpada - reinstaura-se a linha sucessória de Próspero no ducado de Miláo. Seria forçoso ver na Tempestade uma cumplicidade estrutural com a literatura promocional da expansão inglesa, como achamos na coletânea Purchas, his pilgrimes (1613), para dar o exemplo colossal de um verdadeiro ideólogo da colonização inglesa, o organizador Samuel Purchas (cf. ARMITAGE, 2000). Seria igualmente forçoso buscar nela uma condenação do projeto colonial inglês. $\mathrm{O}$ que não quer dizer - até mesmo em razão da sua deslumbrante capacidade de encenar posiçóes políticas contrárias - que a peça não incorpore críticas ao colonialismo. Os ecos de Montaigne são apenas um indício da elaboraçáo dramática de aspectos controversos daquilo que se convencionou chamar, indistintamente, de "discurso colonial."”

O Novo Mundo no espelho do Antigo

O segundo ensaio de Montaigne sobre o Novo Mundo, "De coches" (1588), seja em virtude do título enigmático e da construção errática, tende

7 Sobre ecos de Montaigne em outras peças de Shakespeare, ver o excelente artigo de Arthur KIRSCH (1997). 
a ser relegado ao segundo plano pelos seus leitores e comentadores. A clareza do título e agudeza das afirmaçóes no primeiro, "De canibais" (1580) parecem justificar a preferência moderna. As inversôes de perspectivas enunciadas de modo inesquecível favoreceram uma leitura do ensaio como um texto fundador do moderno enlace entre etnografia e auto-etnografia (MOSER, 2006, p. 112) e de premissas do relativismo cultural (JASMIN, 2019, p. 206-207): “Or je trouve [...] qu'il n'y rien de barbare et de sauvage en cette nation, à ce qu'on m'en a rapporté, sinon que chacun appele barbarie ce qui n'est pas de son usage" (MONTAIGNE, [1580] 1962, I, 31, p. 203). Outra leitura, amplamente difundida, é a de que a reinvenção do tópos do canibalismo por Montaigne poderia ser lida como uma ruptura com a sujeição ao "império" da antiga retórica (cf. BARTHES, 1970) e, portanto, uma afirmação da primazia da experiência. Mas quando se acompanha as experimentaçóes de Montaigne ao longo do ensaio como um todo, percebe-se que há nele dois movimentos distintos. De início, Montaigne contrapóe a autoridade de um informante "simple et grossier" às autoridades textuais, de modo a situar o tópos do canibalismo fora da inventio, do repertório de lugares comuns, para em seguida, através de comparaçóes entre práticas europeias descritas na Bíblia e em narrativas de viagem contemporâneas, reintegrá-los novamente à tradição. Mais importante para a nossa discussão é a parte final do ensaio, em que Montaigne abandona a estrutura exegética do comentário para fazer um relato de viagem, uma "narration particuliere". O que se segue são as lembranças de seu encontro em Rouen, com índios da França Antártica, a antiga colônia francesa na baía de Guanabara (1555-1560). Montaigne usa o relato da sua estadia em Rouen como palco para o encontro utópico dos índios brasileiros com o rei da França. Os viajantes são recebidos calorosamente pelo rei, que lhes pergunta as suas primeiras impressóes da França. A visita utópica dos índios brasileiros em Rouen, inverte a perspectiva dominante sobre o Novo Mundo, transformando os seus habitantes em viajantes curiosos e a França em terra incognita a ser etnografada.

Ao contrário do capítulo sobre os "canibais", no capítulo sobre "coches", Montaigne não se afasta jamais da estrutura do comentário. As suas observações sobre o Novo Mundo remontam sobretudo à tradução francesa da História general de las indias de Lopez de Gómara. ${ }^{8}$ A estrutura do ensaio que se desvia continuamente da matéria anunciada causa certa perplexidade. Um primeiro passo para enfrentá-lo é perceber que o ensaio é dividido em duas partes. Na primeira, o autor discute a sua e a opiniáo de outros sobre a utilidade das carruagens para, em seguida, fazer consideraçóes sobre a pompa e a generosidade, a partir de exemplos antigos e atuais. Na segunda parte,

8 Traduzida por Marc Fumée para o francês: Histoire géneralle des Indes occidentales et terres neuves qui jusquá présent ont esté descouvertes. Paris: M. Sonnius, 1569. 
Montaigne volta a sua atenção para o destino do mundo recém-descoberto: "Nostre monde vien d'en trouver un autre [...] non moins grands, plains et membru que luy, toutefois si nouveu et si enfant qu'on luy aprend enconre son a,b,c." A inversão da justificativa da conquista - a descoberta levará não à salvação, mas à corrupção - que já fora articulada em "De canibais" será agora amplificada e aprofundada. Montaigne receia que o contato com os europeus provocará o seu rápido declínio: "Bien crains-je que nous aurons bien fort hasté sa declinaison et sa ruyne par nostre contagion, et qe nous luy aurons bien cher vendu nos opinions et nos arts." (III, 6, p. 886-887) Mas se no ensaio anterior Montaigne contempla a constituição da França no espelho do Novo Mundo - são os Tupinambá-viajantes que desvendam o seu corpo político - em "De coches", examina o Novo Mundo no espelho da Antiguidade.

O confronto dos mundos novo e antigo resulta da ficção de um encontro utópico entre os antigos gregos e romanos e os americanos, que abre espaço para se vislumbrar, a contrapelo da história, uma colonizaçáo alternativa. Não se trata de uma utopia passada, mas de uma utopia de um futuro passado, que jamais existiu.

Que n'est tombée soubs Alexandre ou soubs ces anciens Grecs et Romains une si noble conqueste, et une si grande mutation et alteration de tant d'empires et de peuples soubs des mains qui eussent doucement poly et defriché ce qu'il y avoit de sauvage, et eussent conforté et promeu les bonnes semences qui nature y avoit produit, meslant no seulement à la culture des terres et ornement des villes les arts de deça, en tant qu'elles y eussent estes necessaires, mais aussi meslant les vertus Grecques et Romaines aux originelles du pays! (III, 6, p. 888)

O método colonial que os antigos gregos e romanos teriam adotado no Novo Mundo parece náo só contrastar a experiência dos antigos com a ignorância dos espanhóis, mas também reunir a maturidade dos antigos à juventude primordial do Novo Mundo. Se Montaigne, no seu ensaio anterior, fizera o elogio do Novo Mundo, da fineza da sua poesia e civilização, assim como da sua "nayfveté si pure et si simple" (I, 31, p. 204), agora parece identificar o Novo Mundo a um estágio de desenvolvimento incompleto, juvenil. $\mathrm{O}$ contato com as artes e virtudes antigas permitiria às almas intocadas e ávidas de conhecimento florescerem - "Combien il eust esté de faire son profit d'ames si neuves, si affanées d'apprentissage, ayant pour la plus part de si beaux commencements naturels!" (III, 6, p. 889) - e instaurarem um modo pacífico e fraterno da vida em comum. O leitor ansioso, nessa passagem, acha que esbarrou nos limites do primitivismo de Montaigne. 
Contudo, as declaraçóes do ensaísta sobre as virtudes e as habilidades artísticas e técnicas dos habitantes do Novo Mundo fazem a comparação mudar de figura. As suas virtudes superariam os exemplos mais notáveis de que se tem notícia - "Quant à la hardiesse et courage, quant à la fermeté, constance, resolution contre les douleurs et la faim et la mort, je ne craindront pas d'opposer les exemples que je trouverois parmy eux aux plus fameux de nostre monde par deçà." (III, 6, p. 887) - e quanto às suas aptidóes artísticas, destaca que nenhuma construção grega, romana ou egípcia competiria com a engenhosidade das obras encontradas ao longo das estradas no Peru (III, 6, p. 893).

O Novo Mundo, ainda jovem, não resiste apenas à comparaçáo com os antigos em sua consumada maturidade; as suas virtudes e a sua engenhosidade os superam. O confronto entre os antigos e os índios americanos, não se resolve, permanece suspenso em contradiçóes. Assim, em virtude da sua irresoluçáo, traz à tona as premissas da comparaçáo entre os mundos e os tempos. É a noçáo mesma de que seja possível reconhecer num dado período o desenvolvimento mais pleno e acabado que Montaigne póe em xeque.

En ces vanitez mesme nous decouvrons combien ces siecles estoyent fertiles d'autres espris que ne sont les nostres. Il va de cette sorte de fertilité comme il faict de tout austres productions de la nature. Ce n'est pas à dire qu'elle y ayt lors employé son dernier effort. Nous n'allons point, nous rodons plustost, et tournoions çà et là. Nous nous promenons sur nos pas. Je crains que nostre cognoissance soit foible en tous sens, nous ne voyons ny gueres loin, ny guere arriere; elle embrasse peu et vit peu, courte et en estandue de temps et en estandue de matiere. (III, 6, p. 885)

A reflexão de Montaigne sobre a precariedade do conhecimento histórico, citada acima, precede a segunda parte do ensaio, dedicada ao Novo Mundo; ela marca uma ponto de articulação de um texto partido ao meio. A segunda metade, também se divide, entre o passado e o futuro do Novo Mundo. Às restriçóes para se conhecer o passado, Montaigne acrescenta dificuldades para se prever o futuro, rejeitando prognósticos como sendo fantasiosos e vãos. Como se desfechasse um golpe decisivo, justapóe a visão de contemporâneos sobre a própria decadência, às profecias do poeta antigo Lucrécio sobre a presumível juventude da sua época, e a concepção do estado originário e juvenil do Novo Mundo ("toutefois si nouveu und si enfant", III, 6, p. 886):

Si nous concluons bien de nostre fin, et ce poëte de la jeunesse de son siecle, cet autre monde ne faira qu'entrer en lumiere quand le nostre en sortira. 
L'univers tombera en paralisie; l'un membre sera perclus; l'autre en vigueur. (III, 6, p. 887)

O sarcasmo de Montaigne volta-se contra as interpretações do futuro que pressupóem a evolução cíclica da história. O experimento lúdicro com o tópos das idades históricas conduz à situação absurda em que o declínio do próprio mundo coincide com o florescimento de outro, à "paralisia" de um universo, ao mesmo tempo, arruinado e vigoroso. A coincidência entre decadência e apogeu é análoga ao encontro imaginado entre os mundos novo e antigo. Uma analogia que inverte o sentido e destitui as bases do encontro utópico, com isso minando a própria ficção da colonização ideal do Mundo Novo pelos antigos.

As reflexôes de Montaigne sobre história não terminam aí. Embora declare de saída as suas reservas em relação às previsóes do futuro, ele as discute detalhadamente como objetos exemplares da capacidade de julgamento. Montaigne interessa-se pelas condiçóes concretas da elaboração de prognósticos. Interessa-se principalmente pelas interpretaçóes do futuro tomadas como resultado de um dilema que transforma o presente em objeto de decisão. São vários os exemplos de prognósticos discutidos no ensaio. Destaco apenas um deles, tomado da história da conquista do reino do Peru. $\mathrm{O}$ aspecto mais notável, nesse caso, é que ele não trata de profecias, mas sim de ameaças, como uma modalidade de previsão do futuro, diretamente voltada para um contexto de ação. À semelhança de prognósticos, ameaças supóem um conhecimento prévio do que ainda virá; mas, diferentemente de prognósticos, são talhadas para provocar, forçar uma determinada açáo. Montaigne descreve como os espanhóis se aproximavam dos indígenas em nome do papa, o representante de deus na terra, que lhes teria concedido a soberania sobre as Índias, e dá a palavra tanto aos espanhóis quanto aos índios, como se quisesse que o leitor acompanhasse os eventos ainda em curso, antes da sua resolução. ${ }^{9}$ Em discurso indireto, reproduz a declaração usual dos espanhóis "leurs remonstrances accoustumées" e a "responce" dos peruanos. Os espanhóis, em nome do rei de Castilha, fazem a sua oferta:

"[....] s'ils vouloient luy estre tributaires, ils seroient très-benignement traictez; leur demandoient des vivres pours leur nourriture, et de l'or pour le besoign de quelque medicine; leur remontroient au demeurant la creance d'un seul Dieu et la verité de nostre religion, laquelle ils leurs conseilloient d'accepter, y adjoustans quelques menasses." (III, 6, p. 889)

9 Sobre o interesse precípuo de Montaigne por situaçóes históricas que em que indivíduos enfrentam dilemas, ver Lyons, 2016: 1: "Montaigne's attention was drawn to moments of suspense that would lead to decisive outcomes, and his use of history anticipates developments in early modern literature and drama in the domains of plausibility and dramatic suspense." 
Montaigne sublinha a diferença da resposta dos peruanos às "declaraçóes" ("remonstrances") e às "ameaças" ("menasses") do invasores espanhóis. À proposição colonial, respondem aquiescentes e céticos; às ameaças, destemidos e altivos:

(...) quant aux menasses, c'estoist signe de faute de jugement d'aller menassant ceux desquels la nature et les moyen estoient inconneux; ainsi qu'ils se despeschassent promptement de vuyder leur terre, car ils n'estoient pas accoustumez des prendre en bonne part les honnestetez et remontrances de gens armez et estrangers; autrement, qu'on feroit d'eux comme de ces autres, leur montrant les testes d'aucuns hommes justiciez autor de leur ville. Voilá un exemple de la balbucie de cette enfance. (III, 6, p. 890)

Os peruanos interpretam as ameaças, que os espanhóis fazem sem conhecer a "natureza" e os "meios" daqueles a que dirigem a ameaça, como um "sinal de falta de capacidade de julgamento". O tom da resposta não é submisso, mas de igual para igual. Respondem às ameaças dos espanhóis com ameaças, de um modo perfeitamente simétrico, também no que diz respeito à ignorância dos seus inimigos. Mesmo assim, a resposta dos peruanos antecipa um conhecimento sobre os conquistadores que será confirmado pela história da conquista, segundo Montaigne. O comentário irônico sobre o "balbucio" - "voilá un exemple de la balbucie de cette enfance" - serve para reforçar a capacidade de julgamento dos peruanos, que ele já reconhecera explicitamente: "La plus part de leurs responces et des negotiations faictes avec eux temoignent qu'ils ne nous devoyent rien en clarté d'esprit naturelle et en pertinence." (III, 6, p. 887) Poderíamos dizer, retomando uma expressão de Montaigne, que o "balbucio" revela uma "inteligência do tempo": as ameaças que fazem aos espanhóis encerram uma previsão do que está por vir, que coincide com o conhecimento de Montaigne sobre o que de fato aconteceria.

Et quand à ces mots: présent, instant, maintenant, par lesquels it semble que principalmente nous soustenouns et fondons l'intelligence du temps, la raison le descouvrant le destruit tout sur le champ: cer elle le fend incontinent et sépare en futur et en passé comme le voulant necessairement desparty en deux. (II, 13, p. 588)

O “presente", o "instante”, e o "agora” são tomados como fundamento do que Montaigne chama de "inteligência do tempo". A expressão é pertinente ao ensaio sobre as carruagens. Afinal, nele, Montaigne enfrenta o presente do Novo Mundo, buscando determinar as condiçóes da sua inteligibilidade, à luz do passado, de futuros passados, e do futuro do presente. O encontro utópico 
entre os antigos e os habitantes do Novo Mundo faz parte do exercício da razão, das justificativas para a tomada de posição em relação aos diferentes tempos.

Quais seriam as implicaçóes do reconhecimento de Montaigne da capacidade de julgamento dos peruanos? Por um lado, esse reconhecimento contradiz o estágio infantil em que supostamente se encontrariam e, por conseguinte, as modalidades da sua afirmação, inclusive o primitivismo do autor. Por outro, a precaução dos indígenas é atribuída à "clareza de espírito natural" ("clarté d'esprit naturelle"), que seria em breve corrompida pelo contato com os conquistadores, reintroduzindo a afirmaçáo do seu estado original. Seja como for: a percepção que os peruanos tiveram do perigo iminente não impediu a sua derrota.

Montaigne encaminha o seu ensaio sobre as carruagens para um fim abrupto, aparentemente, arbitrário, convidando o leitor a fazer com ele o movimento circular da repetição: "Retombons à nos coches." (III, 6, p. 894) Após advertir o seu alocutor de que no Peru não havia veículos e, por isso, as pessoas eram carregadas, narra em frases curtas, incisivas, que um "cavaleiro" agarrou de surpresa o corpo do rei peruano, lançando-o ao chão: "jusques à ce qu'un homme de cheval l'alla saisir au corps, et l'avalla par terre." (III, 6, p. 894) O ensaio, que acaba com a queda do rei, náo oferece nenhuma explicação para a sua derrota. Desse modo, o fim remete ao começo: "Nous ne pouvons nous assurer de la maistresse cause; nous en entassons plusieurs, voir si par rencontre elle se trouvera en ce nombre.” (III, 6, p. 876)

O fim do ensaio confirma a suspeita de que as histórias que Montaigne comenta como exemplos se inscrevem no mesmo espaço de um continuum temporal. O capítulo "De coches" rejeita as premissas de prognósticos e comparaçôes, ironiza as encarnaçôes de idades historicamente determinadas, subjacentes às concepçóes cíclicas de história desde a Antiguidade. Mas ao longo de todo o texto Montaigne argumenta com base em prognósticos e idades históricas. Não abandona o horizonte dos studia humanitatis, ainda que a origem e o futuro do Novo Mundo escapem a essa tradição. Na medida em que nem o seu futuro nem o seu passado são apreensíveis, persiste o dilema do Novo Mundo.

O dilema do Novo Mundo demonstra que o interesse de Montaigne pela história o leva a privilegiar os momentos que antecedem a resolução de eventos históricos. Ao enfocar esses momentos, Montaigne teria antecipado uma estética do suspense (LYONS, 2016, p. 1-19). Mas a estética do suspense náo esgota o dilema do Novo Mundo nos Ensaios. No confronto com o presente do Novo Mundo o que mais importa a Montaigne é o momento de decisão, a dimensão política do exercício da razão. Seja nos encontros utópicos - entre o Novo Mundo e os antigos ou os franceses - ou nos encontros reais - entre os peruanos e os espanhóis - está em jogo a capacidade de julgar. A utopia 
letrada de Montaigne não abandona os studia humanitatis, duvida da sua eficácia, testa os seus limites, servindo-se deles para transformar o presente do Novo Mundo num objeto de decisão, através do exercício inelutável de uma "inteligência do tempo."

\section{Referências}

ARMITAGE, David. The Ideological Origin of the Bristish Empire. Cambridge: Cambridge University Press, 2004.

ARMITAGE, David, CONDREN, Conal, FITZMAURICE, Andrew. "Introduction". In: ARMITAGE, David, Condren, Conal, Fitzmaurice, Andrew (org.). Shakespeare and Early Modern Political Thought. Cambridge: Cambridge University Press, 2009, p. 1-22.

BAARTHES, Roland. L'ancienne rhétorique. Communications, v. 16, p. 172-223, 1970.

CAREY, Daniel e FESTA, Lynn. "Some Answers to the Question: 'What is Postcolonial Enlightenment”. Em: Carey, Daniel e Festa, Lynn (org.). Postcolonial Enlightenment. Eighteenth-Century Colonialism and Postcolonial Theory. Oxford: Oxford University Press, 2009, p. 1-33.

COMPAGNON, Antoine. "L'écriture de l'instant dans les 'Essais", Revue d'Histoire littéraire de la France. 88e Anné, n. 5. p. 839-848, 1988.

FLORIO, John. The Essays or Morall, Poltike and Millitaries Discourss of Lo: Michaell de Montaigne (...). Thir first Booke. Londres, 1603. Disponível em: <https:// www.bl.uk/collection-items/montaignes-essays-translated-by-florio >. Acesso em 15.9.2019.

HAMPTON, Timothy. Montaigne: Writing Against History. In: Writing from History. The Rhetoric o Exemplarity in Renaissance Literature. Ithaca: Cornell University Press, p. 134-197.

HULME, Peter e SHERMAN, William H., (org.). "The Tempest" and its Travels. Philadelphia: University of Pennsylvania Press, 2000.

JASMIN, Marcelo. Civilização e violência. Sobre alguns usos contemporâneos do conceito de civilização. In: Adauto Novaes (org.). Mutaçôes. Dissonâncias do progresso. São Paulo: Edições SESC, 2019, p. 193-207.

KIENING, Christian. O sujeito selvagem. Pequena Poética do Novo Mundo. São Paulo: Edusp, 2014.

KIRSCH, Arthur. Virtue, Vice and Compassion in Montaigne and Shakespeare. $S E L$, v. 37, p. 337-352, 1997. 
KOSELLECK, Reinhart. Historia Magistra Vitae. Über die Auflösung des Topos im Horizont neuzeitlich bewegter Geschichte. In: Vergangene Zukunft. Zur Semantik geschichtlicher Zeiten. Frankfurt a.M.: Suhrkamp, 1989, p. 38-66.

MORE, Thomas. Utopia. Ed. George M. Logan and Robert M. Adams. Cambridge: Cambridge University Press, 2000.

MOSER, Christian. "Autoethnographien: Identitätskonstruktionen im Schwellenbereich von Selbst-und Fremddarstellung”. In: Moser, Christian; Nelles, Jürgen (org.). AutoBioFiktion: Konstruierte Identitäten in Kunst, Literatur und Philosophie. Bielefeld: AisthesisVerlag, 2006, p. 107-143

LYONS, John D. Montaigne and History. Em: Philipe Desan (org.). The Oxford Handbook of Montaigne. Oxford: Oxford University Press, 2016, p. 1-19.

MONTAIGNE, Michel de. Essais. Euvres complètes. Textos estabelecidos por Albert Thibaudet e Maurice Rat. Introdução e notas por Maurice Rat. Paris: Gallimard, 1965. (Coleção Bibliothèque de la Pléiade).

PURCHAS, Samuel. Purchas his pilgrimage. Or Relations of the World and the Religions Observed in all Ages and Places discovered, from the Creation unto this Present. Londres: William Stansby for Henry Featherstone, 1614. [1613].

RICÚPERO, Bernardo. A Tempestade e a América, Lua Nova, São Paulo, n. 93, p. $11-31,2014$.

SHAKESPEARE, William. The Tempest. In: David Bevington et al. (org.). Nova York: Bantam Books, 1988.

THEOBALDO, Maria Cristina. História e exercício em Montaigne. Kriterion, v. 125 , p. 527-541, 2012.

VILLAS BÔAS, Luciana. Os descobrimentos de António Galvão e a utopia letrada no século XVI. In: Thiago Miranda (org.). Libros relege, volve lege. O libro antigo na Biblioteca do Exército. Lisboa: Universidade de Évora, Biblioteca do Exército, 2018.

VILLAS BÔAS, Luciana. O intérprete de Montaigne e a invenção retórica do Novo Mundo. In: Encontros escritos. Semântica histórica do Brasil no Século XVI. (História. Cultura. Ideais). Rio de Janeiro: Editora da Universidade Federal do Rio de Janeiro, 2019, p. 145-62.

Luciana Villas Bôas. Professora Associada do Departamento de Letras AngloGermânicas e do Programa de Pós-Graduação em Ciência da Literatura, na Universidade Federal do Rio de Janeiro. Bolsista da Fundação Alexander von Humboldt.

E-mail: l.villasboas@uol.com.br

Recebido em: 09/10/2019

Aceito em: 30/04/2020 
Errata

No artigo BOAS, Luciana Villas. Utopia, ensaio e tempestade: o novo mundo em Morus, Shakespeare e Montaigne. Alea, Rio de Janeiro, v. 22, n. 2, p. 172-189, 2020. https://doi.org/10.1590/1517-106x/2020222172189.

Na página 172, onde se lia:

Universidade Federal do Rio de Janeiro

Rio de Janeiro, RJ, Brasil

Leia-se:

Universidade Federal do Rio de Janeiro

Departamento de Letras Anglo-Germânicas

Rio de Janeiro, RJ, Brasil 


\section{ERRATA}

Errata

No artigo VILLAS BOAS, Luciana. Utopia, ensaio e tempestade: o novo mundo em Morus, Shakespeare e Montaigne. Alea, Rio de Janeiro, v. 22, n. 2, p. 172-189, 2020. https://doi.org/10.1590/1517-106x/2020222172189.

Na página 172, onde se lia:

Luciana Villas Bôas

Leia-se:

Luciana Villas Bôas 